\title{
A Geografia da Televisão e suas Trocas Simbólicas ${ }^{1}$
}

\author{
The geography of television and its symbolic exchanges
}

Julio Cesar Gonçalves - Universidade de Sorocaba | Sorocaba | SP | Brasil | E-mail: goncaju@uol.com.br|https://orcid.org/0000-0003-1687-7715

Mara Rovida Martini - Universidade de Sorocaba | Sorocaba | SP | Brasil | E-mail: mara.rovida@prof.uniso.br | https://orcid.org/0000-0001-6540-6720

Resumo: Diante da constatação de que no espectro eletromagnético a distribuição dos sinais para transmissões de rádio e TV não acompanha outras formas oficialmente utilizadas nas divisões administrativa, política e territorial do espaço no país, esta pesquisa, ainda em fase inicial, tem como objetivo compreender como se dão as trocas simbólicas entre Sorocaba e Jundiaí, cidades médias que nunca tiveram laços entre si, mas foram unidas pela geografia da televisão. Utilizando-se de metodologia empírico-teórica, tomando como referência a teoria social da mídia de John Thompson e a ressignificação dos espaços geográficos de Milton Santos, o estudo busca identificar qual visibilidade o local ganha na programação da maior rede de televisão do Brasil e como isso repercute nas relações entre sorocabanos e jundiaienses. Os resultados a serem alcançados podem permitir entender as novas relações entre as duas cidades cerca de duas décadas depois de elas terem se ligado pela televisão.

Palavras-chave: Televisão. Geografia. Território simbólico. Relações Sorocaba-Jundiaí.

\begin{abstract}
Given the fact that in the electromagnetic spectrum the distribution of signals for radio and TV transmissions does not follow other means formally used in the administrative, political and territorial divisions of space in the country, this research, still in its initial phase, aims to understand how are the symbolic exchanges between Sorocaba and Jundiaí, average cities that never had ties to each other, but were united by the geography of television. Using an empiricaltheoretical methodology, taking as reference the social media theory of John Thompson and the resignification of Milton Santos geographical spaces, the study seeks to identify which visibility the site gains in the programming of the largest television network in Brazil and how this affects the relations between people from Sorocaba and from Jundiaí. The results to be achieved may make it possible to understand the new relations between the two cities, two decades after they were connected by television.
\end{abstract}

Keywords: Television. Geography. Symbolic Territory. Sorocaba-Jundiaí Relations.

\footnotetext{
${ }^{1}$ A primeira versão deste texto foi apresentada no $17^{\circ}$ Encontro Nacional de Pesquisadores em Jornalismo promovido pela Sociedade Brasileira de Pesquisadores em Jornalismo (SBPJor).
}

- Recebido em: 05 nov. 2019 • Aprovado em: 02 dez. 2019 e-ISSN: 2177-5788

DOI: https://doi.org/10.22484/2177-5788.2019v45n2p373-386

Copyright @ 2019. Conteúdo de acesso aberto, distribuído sob os termos da Licença Internacional da CreativeCommons - CC BY-NC-SA - Atribuição Não Comercial (https://br.creativecommons.org/licencas/) - Permite distribuição e reprodução, desde que atribuam os devido créditos à publicação, ao autor(es) e que licenciem as novas criações sob termos idênticos. 


\section{Introdução}

No espectro das ondas eletromagnéticas, o traçado do mapa do Brasil é outro: a distribuição dos sinais de rádio e TV não acompanha as formas de regionalização adotadas institucionalmente na organização administrativa, política e territorial dos 5.570 municípios brasileiros. Divisas dos estados, limites entre os municípios, bacias hidrográficas, topografia ou mesmo proximidade sociocultural no uso dos espaços urbanos, presentes em outros recortes, não são fatores levados em consideração na distribuição da radiofrequência.

Recurso limitado, que ocupa estreita faixa no amplo espectro eletromagnético - onde se identificam sete tipos de ondas, desde as de baixa frequência, rádio, até as de altíssima frequência, raios gama - a radiofrequência é considerada um bem público e sua administração é de responsabilidade da Agência Nacional de Telecomunicações (Anatel), que regulamenta o uso das telecomunicações no Brasil. É dela a incumbência de disciplinar a utilização dos diversos serviços de comunicação aos quais se prestam essa faixa do espectro, tais como controle do tráfego aéreo e marítimo, satélites, telefonia celular e radiodifusão de sons e imagens.

Conforme os últimos dados divulgados pela agência referentes a 2017, havia 558 geradoras e 13.790 retransmissoras de TV no Brasil. Essas concessionárias - trata-se de um serviço de concessão pública - organizamse em redes nas tarefas de gerar e distribuir sua programação. Existem no Brasil 37 redes nacionais de TV, considerando-se públicas e privadas, que se classificam em geradoras, afiliadas e associadas. As primeiras são as principais e produzem todo o conteúdo nacional. As afiliadas repassam o sinal da emissora, mas estão obrigadas legalmente a produzir conteúdo regional, enquanto as retransmissoras apenas repetem os sinais gerados por ambas.

Ocorre que, como a distribuição da frequência não acompanha as formas de regionalização adotadas por outros critérios, esse conteúdo regional não traduz, necessariamente, o regionalismo ao qual os receptores 
estão habituados. Assim, moradores de uma determinada região, por exemplo, passam a conviver cotidianamente com informações de localidades com as quais não têm ligação alguma, muito embora estejam sintonizados em emissoras classificadas como locais ou regionais.

Esse fato é o ponto de partida para uma pesquisa de doutorado, em fase inicial, no Programa de Pós-Graduação em Comunicação e Cultura da Universidade de Sorocaba à luz da teoria social da mídia, notadamente John B. Thompson.

De um modo fundamental, o uso dos meios de comunicação transforma a organização espacial e temporal da vida social, criando novas formas de ação e interação e novas maneiras de exercer o poder, que não está mais ligado ao partilhamento de um local comum (THOMPSON, 1998, p. 14).

Novas formas de relações sociais e de relacionamentos do indivíduo com o outro e consigo mesmo são criadas com o uso dos meios de comunicação, possibilitando outros tipos de interação, diferentes da interação face a face presentes em nosso cotidiano observa Thompson (1998). A constatação desse fenômeno faz parte do problema dessa pesquisa que se encontra em fase inicial, portanto não se quer com esse texto apresentar resultados, mas sim apresentar as inquietações que fundamental a iniciativa do trabalho.

\section{Território Simbólico}

Levando-se em consideração que o desenvolvimento dos meios de comunicação é "uma reelaboração do caráter simbólico da vida social, uma reorganização dos meios pelos quais os conteúdos simbólicos são produzidos e intercambiados no mundo social" (THOMPSOM, 1998, p. 19), é de se indagar que trocas simbólicas ocorrem nas relações entre cidades que, embora separadas em todas as formas de regionalidade, foram unidas pela regionalização na distribuição dos sinais das ondas eletromagnéticas. 
O que acontece em dois municípios do estado de São Paulo, Sorocaba e Jundiaí, localizadas respectivamente a $98 \mathrm{~km}$ e $59 \mathrm{~km}$ da cidade de São Paulo, demanda que se desenvolvam pesquisas para melhor compreensão desse fenômeno.

Distantes cerca de $90 \mathrm{~km}$ uma de outra, essas cidades têm raízes históricas comuns: fundadas em meados dos anos 1.600, eram habitadas por índios, foram exploradas por bandeirantes, a escravidão indígena está na base de suas economias e até mesmo seus nomes têm origem tupiguarani - Sorocaba é "terra rasgada", Jundiaí "rio dos bagres". Entre fins do século XVIII e meados do século XIX, tal proximidade se desfez: Sorocaba enveredou pelo tropeirismo, Jundiaí entrou na rota da cafeicultura e essas atividades definiram não só o escopo econômico, como certamente também o perfil cultural de cada uma.

Ao longo do século $\mathrm{XX}$, as formas de divisão político-administrativa e geográfica, adotadas pelo Governo do Estado de São Paulo e pelo Instituto Brasileiro de Geografia e Estatística (IBGE) respectivamente, mantiveram essa separação socioespacial entre ambas.

Segundo critérios utilizados pelo governo estadual desde 1967, os 645 municípios paulistas estão distribuídos em 14 Regiões Administrativas (RA), sendo Sorocaba sede de uma delas; Jundiaí faz parte da RA de Campinas. Em 1984 também foram criadas as Regiões de Governo, que atualmente são 14, e ambas as cidades são sedes regionais. Já as Regiões Metropolitanas (RMs) previstas no artigo 153 da Constituição Estadual Paulista (1989), são seis - Sorocaba sedia uma, enquanto Jundiaí é centro de um dos três Aglomerados Urbanos, que complementam a divisão em RMs.

O IBGE, por sua vez, adota metodologia própria no mapeamento territorial brasileiro. Segundo seu critério, desde 2017 o país está dividido em regiões geográficas intermediárias e regiões geográficas imediatas. Tal 
atualização, conforme o instituto, resulta das transformações econômicas ocorridas nas últimas décadas:

A região torna-se, por meio dessa opção, uma construção do conhecimento geográfico, delineada pela dinâmica dos processos de transformação ocorridos recentemente e operacionalizada a partir de elementos concretos (rede urbana, classificação hierárquica dos centros urbanos, detecção dos fluxos de gestão, entre outros), capazes de distinguir espaços regionais em escalas adequadas (IBGE, 2017).

Seguindo essa classificação, o Estado de São Paulo é formado por 11 regiões geográficas intermediárias, que organizam o território e articulam as demais regiões, e 53 regiões geográficas imediatas, que têm na rede urbana seu principal elemento de referência. Sorocaba e Jundiaí não aparecem juntas: ambas são centro de regiões imediatas distintas. Enquanto a primeira encabeça uma das regiões intermediárias, a segunda faz parte da região intermediária de Campinas, composta por 87 municípios.

Quando se faz um recorte para estudo dos recursos hídricos do Estado de São Paulo ambas as cidades estão em grupos distintos: uma faz parte do comitê da Bacia Hidrográfica Sorocaba Médio Tietê, composta por 34 municípios; outra integra o comitê da Bacia Hidrográfica dos rios Piracicaba, Capivari e Jundiaí, formada por 76 cidades.

Igualmente no campo da economia não se identificam regionalizações oficiais que coloquem essas cidades em um mesmo grupo. Embora se possa deduzir que haja um intercâmbio de mercadorias entre ambas, processo inerente à dinâmica de produção e consumo intercidades, na configuração dos Arranjos Produtivos Locais (APL), por exemplo, não existe aproximação entre Sorocaba e Jundiaí.

Instrumento utilizado na definição e execução de políticas públicas para o desenvolvimento econômico microrregional, APLs agrupam empresas de setores afins e de cidades próximas para incrementar atividades econômicas conjuntamente. Em Sorocaba, onde atuam empresas de 25 setores, a prefeitura estuda implantar arranjos produtivos 
nas áreas de bens automotivos, eletrônico e turismo e de imediato articula a criação de um Polo Aeronáutico. Já os arranjos projetados para Jundiaí focam a viticultura.

Entretanto no que diz respeito à geração e distribuição de sinais de TV, as duas cidades estão juntas, apesar de não manterem nenhum outro vínculo entre si. Conforme os critérios adotados pela Anatel, que regulamenta outorgas e concessões do sistema de telecomunicações, Sorocaba e Jundiaí pertencem à mesma faixa de distribuição de sinais de radiofrequência e são cobertas pelas mesmas emissoras.

Duas afiliadas, que têm por obrigatoriedade produzir conteúdo regional, operam no espaço territorial ocupado por Sorocaba e Jundiaí, TV Tem e TV Sorocaba, ligadas às duas maiores redes nacionais, Globo e SBT, respectivamente. Ambas foram autorizadas a funcionar em 1990 e até então as cidades eram cobertas por sinais gerados e transmitidos por emissoras de São Paulo. Jundiaí passou a pertencer à mesma faixa de frequência somente oito anos depois da inauguração das emissoras sorocabanas.

Desde então, cotidianamente os sorocabanos são informados de fatos que acontecem em Jundiaí e seus arredores, da mesma forma que os jundiaienses se inteiram de problemas e eventos de Sorocaba e região, muito embora no que diz respeito à ocupação socioespacial aparentemente haja pouco em comum entre eles.

Mesmo assim, o dia a dia de um está presente na rotina do outro. Um exemplo dessa aproximação entre as cidades pode ser observado nas eleições municipais de 2016: os sorocabanos foram expostos a um debate dos candidatos a prefeito de Jundiaí e uma semana depois os jundiaienses puderam assistir ao debate entre os candidatos sorocabanos. Debates, por sinal, foram um dos principais meios de comunicação dos postulantes ao cargo em Jundiaí diante da inexistência de horário eleitoral gratuito, como 
informou reportagem publicada pela Folha de S. Paulo (TOLEDO, 2016) às vésperas do primeiro turno da eleição de 2016.

Isso acontece porque o município faz parte do grupo de 107 cidades brasileiras com população entre 200 mil e 500 mil habitantes (33,6\% do total) sem uma estação local de TV, como mostram dados apresentados por Pieranti (2018), apontando distorções no planejamento da distribuição de sinais, pois apenas $14,40 \%$ dos municípios brasileiros contam com uma estação local de TV.

Outro exemplo dessa dissintonia entre as duas cidades: Itatiba, a cerca de $120 \mathrm{~km}$ de Sorocaba, está mais perto (a aproximadamente $30 \mathrm{~km}$ ) e sob a influência de Campinas, mas recebe programação de uma emissora sorocabana. Já Indaiatuba, que fica a cerca de $60 \mathrm{~km}$ de Sorocaba e com ela compartilha a produção da montadora Toyota, portanto há significativo intercâmbio entre os dois municípios - o aumento do tráfego de veículos na via Santos Dumont, ligação entre ambos, permite confirmar isso - é coberta por sinais de emissoras campineiras.

A hipótese desta iniciante pesquisa é a de que a regionalização da radiofrequência criou um "território simbólico" entre as duas cidades, levando-se em conta a regionalização dos sinais e as teorias de que a mídia tem grande influência nas instituições sociais e nos processos culturais, da mesma forma que é influenciada por eles. Diante disso, a proposta para a pesquisa é identificar se de fato tem havido trocas simbólicas entre Sorocaba e Jundiaí passadas duas décadas dessa integração pela geografia da televisão, na qual a distribuição do espaço aéreo se distancia das divisões do espaço terrestre como já se frisou.

\section{Busca de Caminhos}

Inicialmente, a constatação que se pode fazer é de que na manifestação dos quatro tipos de poder distinguidos por Thompson (1998), em apenas um deles, o Simbólico, é possível identificar claramente a criação de um vínculo entre essas cidades. Nos demais - Econômico, Político e 
Coercitivo - os laços entre elas não aparecem de forma tão explícita, pois se fazem presentes na política de concessões de uso dos sinais de radiofrequência, ancorada por interesses políticos e econômicos nem tão evidentes, como se verá adiante. "No sentido mais geral, poder é a capacidade de agir para alcançar os próprios objetivos ou interesses, a capacidade de intervir no curso dos acontecimentos e em suas consequências" (THOMPSON, 1998, p. 21).

Essa aproximação entre as duas cidades, portanto, se dá através de um poderoso instrumento de produção de conteúdo simbólico:

Uma das conquistas técnicas da televisão é a sua capacidade de utilizar uma grande quantidade de deixas simbólicas, tanto de tipo auditivo como visual. Enquanto a maioria dos meios técnicos restringe a variedade de deixas simbólicas a um único tipo de forma simbólica (a palavra falada ou escrita), a televisão tem uma riqueza simbólica com características de interação face a face: os comunicadores podem ser vistos ou ouvidos, movimentam-se através do tempo e do espaço da mesma forma que os participantes da interação social e cotidiana, e assim por diante (THOMPSON, 1998, p. 85).

Embora, sobretudo na última década, o uso da internet venha crescendo consideravelmente - a pesquisa do PNAD - Pesquisa Nacional de Amostra por Domicílios -, do IBGE, de 2017, mostrou que 69,3\% dos brasileiros tinham acesso à internet, quase o triplo dos 10,3\% registrados em 2002 - a televisão continua sendo uma das principais fontes de informação da população. Como mostra a última Pesquisa Brasileira de Mídia - Hábitos de Consumo de Mídia pela População Brasileira, divulgada pela Secretaria de Comunicação Social (Secom) do Governo Federal referente ao ano de 2016, a televisão ainda é o principal meio de informação para $63 \%$ da população.

Os reflexos podem ser observados no setor publicitário. De acordo com o Cenp-Meios ${ }^{2}$, que consolida investimentos em mídia feitos através de

\footnotetext{
${ }^{2}$ Ferramenta que mede o investimento nacional em mídia desenvolvida pelo jornal Meio \& Mensagem e pelo Conselho Executivo de Normas Padrão (Cenp), formado por
} 
agências de publicidade, $58,3 \%$ dos $R \$ 16,5$ milhões gastos com propaganda em 2018 foram para a TV aberta.

Em Sorocaba, com uma população estimada de 671.186 habitantes, os aparelhos de TV estão presentes em $97 \%$ dos lares, enquanto em Jundiaí, com 414.810 habitantes, $98 \%$ dos 118.265 domicílios têm esse eletrodoméstico.

Isso posto, o próximo passo é definir de qual tipo de território se está falando. E essa questão de escalas geográficas remete a controvérsias que não cabem ser aprofundadas neste momento.

Assim como já salientaram David Harvey e outros, "as escalas não são imutáveis, muito menos naturais"; elas são, muito pelo contrário, produtos de mudanças tecnológicas, de modos de organização humana e da luta política (apud Souza, 2013, p. 191). Por isso qualquer proposta de tipologia serve apenas para situar os recortes espaciais e orientar as escolhas dos níveis de análise e terá sempre que ser relativizada de acordo com o contexto específico de cada pesquisa. Nessa perspectiva, escala é vista aqui como um instrumento metodológico de mão dupla, que pode partir dos desdobramentos de lugar (cidade, aldeia, bairro, quarteirão, rua, etc.) ou da totalidade do global (mundo, nação, região, lugar) (AGUIAR, 2016, p. 56).

Em se tratando da demarcação de um espaço via comunicação mediada, outras expressões, como "regional" e "local", também são utilizadas e igualmente carecem de uma definição mais precisa. Em 1956, durante o IV Congresso Nacional de Jornalistas, Milton Santos apresentou uma classificação funcional dos jornais brasileiros, categorizando-os em nacional, estadual, regional e local - foi uma das primeiras referências no assunto. Mas seu foco eram os jornais impressos e decorridos cerca de 70 anos o uso da tecnologia transformou a mídia e hoje já há até quem aposte

representantes de agências, veículos e anunciantes para assegurar boas práticas comerciais no setor 
no fim dos impressos. Mas a palavra certa até hoje não encontrou espaço nesse vocabulário.

Em estudo no qual demonstra que novos arranjos e inter-relações dos grupos de mídia estão criando uma "regionalização midiática" no Brasil, Aguiar (2016) deparou-se com o uso indiscriminado de expressões como "jornalismo local", "jornalismo regional" e "jornalismo do interior" traduzindo indistintamente um mesmo contexto ou usadas como tentativas de diferenciar realidades iguais.

Isso ocorre porque, em seus ciclos de vida, morte e ressurreição, o conceito de região foi se tornando polissêmico, especialmente no senso comum, como observou o geógrafo Rogerio Haesbert. Segundo ele, a raiz do termo, "regere", remete às relações de poder envolvidas nos processos socioespaciais. "Toda regionalização deve ser considerada, também, um ato de poder - o poder de recortar, de classificar e, muitas vezes o de nomear" (HAESBERT, 2010 apud AGUIAR, 2016, p. 42).

Foi essa polissemia um dos fatores que motivaram Aguiar a aproximar referenciais teóricos e metodológicos da comunicação e dos estudos de jornalismo aos conceitos-chave da geografia, como espaço, território, região e escala. E a propor recortes espaciais para uma classificação, subdividindo essas escalas em vários níveis. Nessa sua categorização, por exemplo, a escala local vai do hiperlocal - unidade habitacional, rua, quadra - ao macrolocal, no caso de metrópoles ou regiões metropolitanas.

Não obstante essa proposta, a autora conclui que regionalizar não significa apenas dividir, mas ressignificar parcelas de territórios

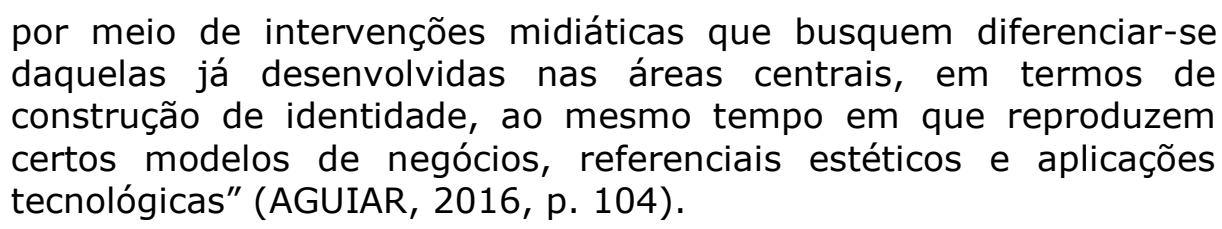

por meio de intervenções midiáticas que busquem diferenciar-se daquelas já desenvolvidas nas áreas centrais, em termos de construção de identidade, ao mesmo tempo em que reproduzem tecnológicas" (AGUIAR, 2016, p. 104).

Dessa forma, embora não seja possível identificar outros vínculos entre Sorocaba e Jundiaí a não ser uma remota origem histórica tupi- 
guarani, a ligação de ambas pelas ondas eletromagnéticas pode se constituir em um território simbólico, na medida em que, como observou Santos (2006, p. 69):

O movimento da sociedade, atribuindo novas funções às formas geográficas, transformam a organização do espaço, criam novas situações de equilíbrio e ao mesmo tempo novos pontos de partida para um novo movimento. Por adquirirem uma vida, sempre renovada pelos movimentos sociais, as formas - tornadas assim formaconteúdo - podem participar de uma dialética com a própria sociedade e assim fazer parte da própria evolução de espaço.

Ou seja, é preciso procurar entender esse rearranjo socioespacial como ponto de partida para um novo movimento, mas para tanto há necessidade de decifrar as entranhas desse movimento. Isso obrigatoriamente passa pela política de concessão de emissoras de rádio e TV no Brasil.

Interesses políticos e econômicos estão por trás dessas concessões. Tanto assim que a Lei 9.472/97 (BRASIL, 1997), que organiza e regula a telecomunicação no país e institui a criação da agência reguladora, faz uma distinção no que diz respeito às concessões para rádio e TV:

A outorga dos serviços de radiodifusão de sons e imagens fica excluída da jurisdição da agência, permanecendo no âmbito de competência do Poder Executivo, devendo a agência elaborar e manter os respectivos planos de distribuição de canais, levando em conta, inclusive, os aspectos concernentes à evolução tecnológica (ALARCON, 2005).

Isso vale ainda hoje, embora em 2017 a Anatel tenha divulgado a resolução n. 671, estabelecendo novos parâmetros para a administração, condições de uso, autorização e controle de radiofrequências. Mesmo com a mudança do sinal analógico para o digital, continuou mais do mesmo:

De acordo com Kucinski (1998), o controle das concessões está nas mãos da elite dominante, e isso ocorre porque grande parte das permissões foi distribuída com intuitos políticos. Segundo o autor, durante a Presidência do general João Figueiredo (1979 a 1985) 634 concessões de rádio e televisão foram dadas para congressistas ou aliados do governo, com a intenção de garantir a derrota da emenda Dante de Oliveira. Outra distribuição em massa com interesses políticos aconteceu no governo de José Sarney (1985 a 1990), sucessor de Figueiredo, durante a chamada "Nova República", quando 
pelo menos 1.028 concessões de rádio e televisão foram distribuídas, sendo que, destas, 539 foram entregues a congressistas e aliados do então Presidente (SOMMA; CALEFFI; DIAS, 2015).

O resultado disso é que a concentração de mídia no país assume contornos preocupantes, como alerta o estudo "Quem controla a Mídia no Brasil", elaborado pela Intervozes e Repórter sem Fronteiras ${ }^{3}$. Foram analisados os 50 veículos de comunicação de maior audiência no país e todos pertencem a grupos que possuem interesses econômicos - sobretudo nos setores de educação, saúde, imobiliário, financeiro, de energia e agrário - políticos e religiosos. "No Brasil, o resultado indica alerta vermelho. Nosso sistema de mídia mostra alta concentração de audiência e de propriedade, alta concentração geográfica, falta de transparência, além de interferências econômicas, políticas e religiosas" (MÉDIA OWNERSHIP MONITOR, 2017, p. 1).

Portanto, é nesse contexto que se pretende analisar a criação de um território simbólico entre as cidades de Sorocaba e Jundiaí.

\section{Considerações Finais}

O que se buscou aqui foi alinhar alguns pontos dessa pesquisa que se está iniciando. Há ainda longo caminho a ser percorrido, a partir do estabelecimento de vínculos e desvínculos sociais, culturais e econômicos entre as cidades de Sorocaba e Jundiaí, a partir de suas origens, até a demarcação de um território simbólico entre ambas.

A delimitação desse território, como se pode constatar, vai exigir um diálogo com a geografia, no sentido de explicitar conceitos como escala geográfica, território, territorialidade, regional ou local, expressões que mesmo no campo de estudo da geografia não têm definições consensuais.

\footnotetext{
${ }^{3}$ Intervozes é uma associação brasileira que trabalha pela efetivação do direito humano à comunicação e Repórter Sem Fronteiras uma ONG internacional que atua em defesa da liberdade de imprensa, parceiras no Brasil no projeto MOM, que monitora a concentração da mídia globalmente
} 
E na comunicação são utilizadas ora para diferenciar coisas semelhantes, ora para igualar situações que não são iguais.

É preciso, ainda, discutir as metodologias adotadas por diversas instituições nos recortes geográficos para delimitação e regionalização do espaço entre municípios e regiões e compreender as especificidades de cada recorte. Instituições aqui entendidas com base no conceito de Thompson (1998), que as caracteriza como um conjunto de regras, recursos e relações que as mantém unidas para atingir resultados globais.

Outra questão que obrigatoriamente deve ser analisada para este estudo é a política de concessão de rádio e TV no Brasil, para melhor explicitar os interesses que norteiam a distribuição de emissoras de TV. Episódios como o que ocorreu recentemente em Alagoas são raros: a concessão da TV Gazeta, pertencente ao senador Fernando Collor e afiliada à Rede Globo, foi cassada pela 13a Vara Federal após ação do Ministério Público motivada pela denúncia de 13 organizações ligadas à comunicação que desde 2015 ajuizaram 40 parlamentares (32 deputados federais e 8 senadores) por comandarem emissoras de radiodifusão (DONO..., 2019). A prática é vetada pelo artigo 54 da Constituição, mas sempre foi e continua sendo ignorada nos processos de concessão.

Há também necessidade de identificar em que outros espaços essa territorialidade simbólica ocorre no Estado de São Paulo, para compreender melhor esse processo, conforme os dados apresentados por Pieranti (2018), 15 dos 107 municípios brasileiros com população entre 200 mil e 500 mil habitantes que não têm estações locais de TV estão localizados em São Paulo, o que faz supor que territórios simbólicos podem ter capilaridade em todo estado.

O que se expôs aqui é um esboço da trajetória que se pretende seguir para o desenvolvimento desta pesquisa, que tem o propósito de colaborar com a reflexão sobre a produção científica e profissional no campo da comunicação, bem como incentivar reflexões sobre as mudanças sociais 
resultantes da interação entre mídia e sociedade na comunidade a qual estamos inseridos.

\section{Referências}

AGÊNCIA NACIONAL DE TELECOMUNICAÇÕES. Radiofrequências: leilões de radiofrequência podem mudar para popularizar serviços. Disponível em: https://www.senado.gov.br/noticias/Jornal/emdiscussao/banda-larga/mercado telecomunicacoes/radiofrequencias.aspx. Acesso em: 17 jun. 2019.

AGUIAR, Sonia. Territórios do jornalismo. Petrópolis: Vozes, 2016.

ALARCON, Anderson de O. A televisão e o instituto da concessão pública.

JusBrasil. 2005. Disponível em: https://jus.com.br/artigos/7654/a-televisao-eo-instituto-da-concessao-publica. Acesso em: 24 jul. 2019.

BRASIL. Decreto $n^{\circ}$. 9.472, de 16 de julho de 1997. Organização dos serviços de telecomunicações, criação e funcionamento de órgão regulador. Brasília, 1997.

DONO de afiliada da Globo, Collor perde concessão de rádio e TV por decisão judicial. Revista Fórum, Santos, 11 jul., 2019. Disponível em: https://revistaforum.com.br/comunicacao/dono-de-afiliada-da-globo-emalagoas-collor-perde-concessao-de-radio-e-tv-por-decisao-judicial/ . Acesso em: 12 jul. 2019.

INSTITUTO BRASILEIRO DE GEOGRAFIA E ESTATISTICA. Divisão Regional do Brasil em regiões geográficas imediatas e regiões geografias intermediárias. Rio de Janeiro: IBGE, 2017.

MÉDIA OWNERSHIP MONITOR. Intervozes: coletivo Brasil de Comunicação Social. Repórteres sem Fronteira pela liberdade da Informação. Quem controla a mídia no Brasil? São Paulo, 2017. p. 1. Disponível em: http://brazil.momrsf.org/br/. Acesso em: 15 abr. 2019.

PIERANTI, Octavio P. A distribuição geográfica das estações locais de TV no Brasil. Famecos, Rio Grande do Sul, v. 25, n. 3, p. 1-19, 2018. Disponível em: http://revistaseletronicas.pucrs.br/ojs/index.php/revistafamecos/article/view/30 181. Acesso em: $10 \mathrm{dez} .2019$.

SANTOS, Milton. A natureza do espaço. São Paulo: Editora USP, 2006. SÃO PAULO (Estado). Constituição Estadual Paulista. São Paulo: Assembleia Legislativa, 1989.

SOMMA NETO, João; CALEFFI, Renata; DIAS E. C. Política e televisão: sistema de meios e concessões públicas no Brasil e na Argentina. Comunicação Pública, Lisboa, v. 10, n. 17, 2015. Disponível em: https://journals.openedition.org/cp/949. Acesso em: 10 dez. 2019.

THOMPSON, John B. A mídia e a modernidade. Petrópolis: Vozes, 1998.

TOLEDO, Marcelo. Em Jundiaí, onde não há geradora de TV local, debates movem a disputa eleitoral. Folha de S. Paulo, São Paulo, 24 out. 2016. Disponível em: https://www1.folha.uol.com.br/poder/eleicoes2016/2016/10/1825671-em-jundiai-onde-nao-ha-geradora-de-tv local-debatesmovem-disputa-eleitor. Acesso em: 1 maio 2019. 